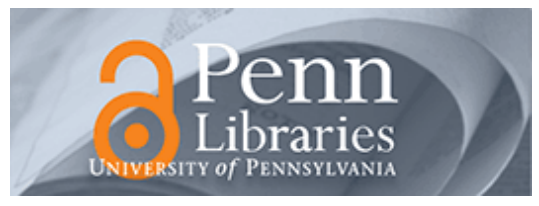

University of Pennsylvania

ScholarlyCommons

Marketing Papers

Wharton Faculty Research

April 1988

\title{
Communication of Research on Forecasting: The Journal
}

\author{
J. Scott Armstrong \\ University of Pennsylvania, armstrong@wharton.upenn.edu
}

Follow this and additional works at: https://repository.upenn.edu/marketing_papers

\section{Recommended Citation}

Armstrong, J. S. (1988). Communication of Research on Forecasting: The Journal. Retrieved from https://repository.upenn.edu/marketing_papers/71

Postprint version. Published in International Journal of Forecasting, Volume 4, Issue 3, April 1988, pages 321-324.

Publisher URL: http://dx.doi.org/10.1016/0169-2070(88)90099-4

This paper is posted at ScholarlyCommons. https://repository.upenn.edu/marketing_papers/71

For more information, please contact repository@pobox.upenn.edu. 


\title{
Communication of Research on Forecasting: The Journal
}

\author{
Abstract \\ It seems trivial to point out that one of the major goals of the International Institute of Forecasters is to \\ communicate research findings. In particular, the IIF tries to foster communication among researchers, \\ between researchers and practitioners, across nationalities, and across disciplines. We have two major \\ vehicles for this: the annual symposiums and the journal. This editorial examines the results that we have \\ had to date with our journals.

\section{Comments} \\ Postprint version. Published in International Journal of Forecasting, Volume 4, Issue 3, April 1988, pages \\ 321-324. \\ Publisher URL: http://dx.doi.org/10.1016/0169-2070(88)90099-4
}


Published in International Journal of Forecasting, 4 (1988), 321-324

\title{
Communication of Research on Forecasting: The Journal
}

\author{
J. Scott Armstrong ${ }^{1}$ \\ The Wharton School, University of Pennsylvania, Philadelphia, PA 19104-6371, USA
}

It seems trivial to point out that one of the major goals of the International Institute of Forecasters is to communicate research findings. In particular, the IIF tries to foster communication among researchers, between researchers and practitioners, across nationalities, and across disciplines. We have two major vehicles for this: the annual symposiums and the journal. This editorial examines the results that we have had to date with our journals.

The IIF founded the Journal of Forecasting in 1982 and edited it until early 1985. In an effort to provide better quality and more timely service, we changed publishers in 1985 and founded the International Journal of Forecasting. How successful have these journals been in communicating research findings?

To assess the success of the journals in communicating, we conducted a survey in April 1986 of the members of the International Institute of Forecasters (IIF). The questionnaire was sent out in a one-shot multipurpose mailing. This mailing contained a news memo and four other items. Unfortunately, it yielded only 201 responses (a 15\% rate of return). These respondents, we presume, are those who are most interested in the activities of the IIF.

The journals reached a substantial audience. By 1984, the Journal of Forecasting had about 1,700 subscribers. A high proportion of these subscriptions came from libraries. As a result, the number of readers is likely to be in excess of 2,000 .

If the papers are not read, a journal fails to communicate. The survey indicated that the papers are read. On average, the respondents reported reading 2.4 papers per issue. This represents about $1 / 3$ of the papers. Given the diversity of our audience, this impressed us as a high readership rate.

Papers were read by practitioners and academics, though more by the practitioners (2.6 vs. 2.2). Readership was also balanced between our U.S. and foreign members, though somewhat higher among the former (2.5 vs. 2.2). Thus, the journal appears to be meeting the needs of its various constituents.

Readership was high for the "Book Reviews;" only 5\% of the readers ignored the book reviews, while about $22 \%$ always read them. On a $1=$ "never" to $5=$ "always" scale, the book review readership index was 3.4. A similar picture emerged for the summaries of "Research on Forecasting," the short reviews of papers published in other journals: only $2 \%$ of the readers ignored these, while $22 \%$ always read them. The readership index for these research reviews was 3.5. We infer from the results that the rate of readership is higher for these two sections than it is for the journals' papers.

Reading is necessary, but not sufficient. Do the readers understand what they read? The journal has an objective to publish papers that are readable. The operational goal was that each paper should not exceed a Gunning Fog Index of 16 (requiring 16 years of education for understanding). The journal came close to that goal on its first issue in 1982, when the fog index averaged 17.0. In 1985 (using the first issue of the Journal of Forecasting and the first volume of the new International Journal of Forecasting), the fog index was 16.4. For the period from 1985-87, the average fog index was less than 16 . The journals are, then, coming close to our standards for readability.

We also obtained evidence on readability from the IIF survey. When asked to rate the readability of these journals, respondents gave them a 3.7 on a scale from 1 = " poorly written" to 5 = "extremely well- written."

\footnotetext{
${ }^{1}$ Acknowledgement: Our thanks to Dr. Martha Lightwood, who has improved the quality or our copy editing. In addition, she has assisted in the preparation of the new "Instructions to Authors."
} 
Academics rated the papers as somewhat more readable than did practitioners (3.8 vs. 3.6). Non-U.S. readers rated readability slightly higher than did the U.S. readers (3.8 vs. 3.6).

They read, they understand, ... but do they regard the content as important? A common criticism of academic papers in some journals is that they resemble "trivial pursuit." On a scale from 1= "of no importance" to 5 $=$ "extremely important", the respondents rated the papers' importance as 3.5. Academics rated them as more important than did the practitioners (3.7 vs. 3.3). Nevertheless, the journals seem to be meeting the needs of each group. The importance ratings were the same for U.S. and non-U.S. respondents.

The respondents reported that they were "satisfied" with the content in the journals. On a scale from $1=$ "very dissatisfied" to $5=$ "very satisfied," U.S. practitioners reported 3.3, foreign practitioners 3.7, foreign academics 3.7, and U.S. academics 3.8. The critical question, however, is whether the readers use the material in the journals. One of the major aims of the journal is to "b ridge the gap between theory and practice." The survey provided evidence that the journal is meeting the needs of the academics and the practitioners (see Exhibit 1). As would be expected, the pattern of use differed substantially between the academics and practitioners. Many practitioners (about 1/3) made applications on the job. Academics used the findings in their research $(27 \%$ cited at least one paper) and in their teaching (25\%).

\section{Exhibit 1}

Use of findings or techniques (reported as \% of the 201 respondents*).

\begin{tabular}{lcc}
\hline Area of use & Practitioners & Academics \\
\hline Tried application on my job & 36 & 5 \\
Successful application on my job & 18 & 4 \\
Cited the work in my research & 13 & 27 \\
Did additional research on topic & 9 & 19 \\
Used in my teaching & 5 & 25 \\
\hline
\end{tabular}

${ }^{*}$ Respondents could, and often did, report more than one area of use.

The favorable results on high citation rates from Exhibit 1 are supported by the SSCI Journal Citation Reports. This index showed that our original journal had one of the highest citation impact factors among journals in management, business, and planning. Of 84 journals in these categories, the Journal of Forecasting ranked 7th, almost in a tie for 6th with Organizational Behavior and Human Performance.

Overall, the journal is doing a good job of communicating across the boundaries of its diverse audience. Nevertheless, we think much more can be done. This year's volume incorporates some design changes that should make the papers more readable. We have also revised the "Instructions to Authors" to emphasize readability and full disclosure. The Instructions are provided in Exhibit 2 and they will be reprinted on the inside back cover of each issue.

Exhibit 2

Instructions to authors: International Journal of Forecasting.

(1) Papers must be in English or French. Write in a concise manner. Referees will be asked to consider the value of the paper relative to its length.

(2) Submission of a paper implies that it contains original work that has not previously been published and that is not being submitted for publication elsewhere. Publication in a limited distribution "Proceedings" does not disqualify a paper. If the author has published Similar findings elsewhere, please cite and explain how the current paper differs.

(3) Submit four copies of the paper to any of the four editors (not to associate editors). See addresses on the inside front cover of each issue. The editors do not accept responsibility for damage or loss of papers submitted.

(4) Double space everything. Type on one side only. Use wide margins. 
(5) The first page should contain the title of the paper and each author's name, affiliation, address, and telephone number. Correspondence will be with the first author unless requested otherwise.

(6) The second page should give only a brief descriptive title.

(7) The third page should contain an abstract of not more than 150 words. Summarize the principal findings and how they were obtained. Explain why the findings are important for researchers and for practitioners. Be specific.

(8) Key words should also appear on the third page.

(9) Provide a biographical sketch of fewer than 100 words for each author.

(10) Start the paper on the fourth page; do not relist title or authors.

(11) Use major and minor headings to aid readability. (The introduction should not be headed.) Headings should be short. Side headings should be underlined. Paragraph headings should be underlined, followed by a colon.

(12) Footnotes should be kept to a minimum. If used, they should be numbered consecutively and placed after the references.

(13) References should include only relevant sources, presumably those with evidence or methodology. In the text, references should appear for papers as "Klein (1984)", or for books as "Box and Jenkins (1970, p. 245)". At the end of the manuscript, the reference should be listed alphabetically by surname of the first author. Use the following format:

For articles: Gardner, Everette, S., Jr. and E. McKenzie, 1985, "Forecasting trends in time series," Management Science, 31, 1237-1246.

For books: Cook, Thomas D. and Donald T. Campbell, 1979, Quasi-Experimentation (Houghton Mifflin: Boston).

For collective works: Kahneman, Daniel and Amos Tversky, "Intuitive prediction: Biases and corrective procedures," in Daniel Kahneman, Paul Slovic and Amos Tversky, Ed s., 1982, Judgment Under Uncertainty: Heuristics and Biases (Cambridge University Press: Cambridge, England), 414-421.

Authors should ensure that there is a strict one-to-one correspondence between the authors' names (years) in the text and those in the reference list.

(14) In general, only published papers should be cited. If unpublished, indicate how copies may be obtained.

(15) Use simple notation. Our readership crosses many disciplines. Avoid unusual symbols and Greek letters if possible.

(16) If mathematical derivations are needed, put them in an appendix.

(17) Quotations should be kept to a minimum. Authors must obtain written permission from the publisher to use a quotation that exceeds 250 words.

(18) Tables and Figures should be labeled "Exhibits" and be placed on separate pages. Exhibits should be photo ready with descriptive headings. If the exhibit involves a table, provide explanatory labels for the rows and columns. Place exhibits at the end of the paper, and mark the exhibit number, title of paper, and name of author on the back. Illustrations that have to be redrawn by the publisher will be charged to the author. 
(19) Simplify the presentation of data! Round data to no more than three digits. Organize tables and charts to aid understanding.

(20) Readability is important, especially in that the readers come from different countries, disciplines, and types of institutions. One way to assess readability is the Gunning Fog Index. It provides the educational grade level needed to understand the material. The formula is:

$$
\mathrm{G}=0.4(\mathrm{~S}+\mathrm{W})
$$

where $\mathrm{S}$ is the average sentence length (words per sentence) and $\mathrm{W}$ is the percentage of words with 3 or more syllables (not counting common prefixes and suffixes). Try to keep the index for your paper below 16. Guidelines for effective and simple writing can be found in William Strunk, Jr. and E. B White, 1979, The Elements of Style. New York: Macmillan.

(21) Authors should fully disclose their methods and data. Due to space limitations, it is often advisable to provide the data to the editors separately to put on file. Tell readers how to obtain additional details. The disclosure of data will be considered in the decision of whether to publish the paper.

(22) Evidence of prior peer review is helpful, such as a listing of the occasions on which this paper has been presented, and a list of colleagues who have reviewed the paper.

(23) Authors are invited to provide names, addresses, and fields of interest of 4 to 6 persons outside their own institution who are qualified to act as referees. We will try to use at least one of these as a referee.

(24) After acceptance of the paper, all correspondence should be addressed to the Editor- in-Chief.

(25) Page proofs will be sent to the (first) author. Please proofread carefully. 